\title{
Assessment of drug-related problems among type 2 diabetic patients on follow up at Hiwot Fana Specialized University Hospital, Harar, Eastern Ethiopia
}

\author{
Haymen Abdulmalik, Yohannes Tadiwos ${ }^{*}$ (1) and Nanati Legese
}

\begin{abstract}
Objectives: To assess the drug-related problem among patients with type 2 diabetes at Hiwot Fana Specialized University Hospital.

Results: In this study, a total of 148 patient medication records were included. More than half, 83 (57.4\%) were men and the rest 65 (42.6\%) were women. The mean age of the study participants was 51.26 \pm 7.08 . Around one-third (74.3\%) of the participants had urban residency. A total of 127 drug-related problems were identified, of which dosage too low was the most common type of DRP encountered, 46 (36.2\%), followed by unnecessary drug therapy, 25 (19.7\%) and ineffective drug therapy, 25 (19.7\%). 95 (64.2\%) of the patients had at least one drug-related problem. Among patients with DRP, more than half of them, 59 (62.1\%) had a single DRP. Out of the total participants, 85 (57.4\%) of them were taking one anti-diabetic medication and 63 (42.6\%) of them dual anti-diabetic medications. Only half of the patients have attained the desired FBG level. There was no patient who had experienced more than two types of drug-related problems at a time. Less than $10 \%$ of patients were taking five or more drugs at a time.
\end{abstract}

Keywords: Diabetes mellitus, Drug therapy problem, Hiwot Fana Specialized University Hospital

\section{Introduction}

Type 2 diabetes mellitus (DM) is associated with an increase in blood glucose resulting from a defect in insulin secretion and insulin action and with a resulting disturbance in carbohydrate, fat and protein metabolism [1-4]. Both the number of cases and the prevalence of diabetes have been steadily increasing over the past few decades [5, 6].

For the treatment of T2DM, varieties of drugs with a different mechanism of action are used to maintain glycemic control [7]. Patients with T2DM are at risk of drugrelated problems (DRP), which can happen at any step during the treatment process [8-10] and it affects the therapeutic outcome $[3,11]$. Problems associated with

\footnotetext{
*Correspondence: ytadios@yahoo.com

School of Pharmacy, College of Health and Medical Sciences, Haramaya

University, P.O. Box 235, Harar, Ethiopia
}

drug use are many and are classified into different system by different researchers [12] and include untreated condition, inappropriate choice of drugs, unnecessary drug therapy, failure to receive drug, discrepancies between prescribed and actual regimens, overdose, adverse drug reactions (ADRs), inappropriate medication prescribing, and drug use, drug interactions [8].

There exists a problem in the prescribing, dispensing and usage of drugs [8] resulting in the unwanted effect of medications [13]. This with the ineffectiveness of the drugs chosen makes the management of DM challenging [12]. Multiple co-morbidities, increasing age and the number of medications taken by DM patients increase the risk of DRP $[6,10,14,15]$. Other factors such as renal impairment, poor lipid control, cardiovascular disease, and the duration of hospital stay also increase DRP risk $[16,17]$. DRP is a worldwide health problem that compromises the quality of life, increase hospitalization, 
increase overall health care cost and mortality $[8,9,12$, $18,19]$.

This study tries to assess DRPs among T2DM patients on follow up at Hiwot Fana Specialized Hospital (HFSUH). Identifying the DRP and optimizing drug treatment helps to facilitate the rational use of the drugs and help patients to achieve their goals of therapy.

\section{Main text}

\section{Methodology}

\section{Study design and study setting}

A facility-based retrospective cross-sectional study was conducted at HFSUH by reviewing the medical records of T2DM outpatients on chronic follow up from JulyDecember 2018 G.C at HFSUH.

\section{Study population}

Patients diagnosed with T2DM aged 18 years or older of both gender and receiving at least one anti-diabetic medication and those who had been on treatment for at least 3 months at HFSUH during the data collection period were included in the study. Patients with missing or incomplete data were excluded.

\section{Sample size determination and sampling technique}

The sample size was 148 calculated using a single population proportion formula, with a prevalence of $45.9 \%$ based on the previous study done in Addis Ababa, at Tikur Anbessa Specialized Hospital (TASH) [20] and the total number of T2DM on follow up at HFSUH was 211. The patient medical record (PMR) was selected using a simple random sampling technique.

\section{Data collection method and procedure}

The record of patients with T2DM patients on chronic follow-up from July-December 2018 G.C at HFSUH was identified until the targeted sample size was achieved. The required information was collected by the principal investigator from the PMR using a structured data collection checklist. Cipolle's method of DRP classification system was used together with the Ethiopian treatment Guideline and standards of medical care for diabetes.

\section{Data processing and analysis}

Data were checked for completeness by the principal investigator (PI) on a daily basis during collection before actual analysis. The analysis was done using statistical software for social sciences (SPSS) 20.

\section{Operational definition}

DRP: Refers to any unwanted incident related to medication therapy that actually or potentially affects the desired goals of treatment [12].
Cipolle's method: It classifies DRPs into seven major groups as follows: These include: including unnecessary drug therapy, needs additional drug therapy, ineffective drug therapy, dosage too low, adverse drug reaction, dosage too high and noncompliance [21].

\section{The DRPs were defined as follows:}

Dosage too high: If the prescribed dose was too high than the recommended dose by standard treatment guideline of Ethiopia [22].

Dosage too low: If the prescribed dose was less than the recommended dose by standard treatment guideline of Ethiopia [22].

Unnecessary drug therapy: If there is duplication of therapy or unwanted addition of medication or if the patient doesn't have an indication for adding another medication.

Needs additional drug therapy: If a patient was inadequately medicated with his/her blood glucose not within the target range $(80-130 \mathrm{mg} / \mathrm{dL})$, this was classified as needs additional drug therapy.

ADR: Adequate doses resulting in unpleasant or harmful reactions.

Ineffective drug therapy: The inappropriate use of drugs according to standard treatment guideline of Ethiopia [22].

\section{Result}

In this study, a total of 148 T2DM PMR were included. More than half, $83(57.4 \%)$ were males and the rest 65 $(42.6 \%)$ were females. The mean age of the study participants was $51.26 \pm 7.08$. Around one-third (74.3\%) of the participants had urban residency. More than half of the patients $(58.1 \%)$ had a duration of illness 1 up to 5 years. The overall mean $( \pm S D)$ average value of FBG for the last three consecutive visits was $129.14 \pm 31.621$. Half of the participants (50\%) meet the intended glycaemic FBG target and 66 (44.6\%) of them recorded above $>130 \mathrm{mg} /$ dL. Out of the total study participants, 51 (34.5\%) had comorbid medical problems. The most common comorbid disease was hypertension 30 (20.3\%), followed by CHF 7 (4.7\%). Only 9 (6.1\%) participants had developed chronic diabetes complications and of these, 7 (77.8\%) of them encountered diabetic peripheral neuropathy (Table 1).

Out of the total participants, 85 (57.4\%) of them were taking one anti-diabetic medication, from these metformin and basal insulin accounts for 55 (37.2\%) and 24 (16.2\%) respectively. Dual anti-diabetic medications were used in $63(42.6 \%)$ cases and metformin with Glibenclamide were used for 41 (27.7\%) cases, followed by metformin with basal insulin in 19 (12.8\%) cases. A total of 113 drugs were found in the patient chart for chronic 
Table 1 Socio-demographic and clinical characteristics of ambulatory patients with type 2 diabetes on follow up from July to December 2018 at HFSUH, Harar, Ethiopia

\begin{tabular}{|c|c|c|}
\hline Variables & Frequency & Percentage \\
\hline \multicolumn{3}{|l|}{ Age } \\
\hline $20-40$ & 11 & 7.4 \\
\hline $41-60$ & 124 & 83.8 \\
\hline$\geq 61$ & 13 & 8.8 \\
\hline Total & 148 & 100 \\
\hline \multicolumn{3}{|l|}{ Sex } \\
\hline Male & 83 & 57.4 \\
\hline Female & 65 & 42.6 \\
\hline Total & 148 & 100 \\
\hline \multicolumn{3}{|l|}{ Residency } \\
\hline Urban (Harar) & 110 & 74.3 \\
\hline Rural & 38 & 25.7 \\
\hline Total & 148 & 100 \\
\hline \multicolumn{3}{|c|}{ Duration of diabetes } \\
\hline$<1$ year & 33 & 22.3 \\
\hline $1-5$ years & 86 & 58.1 \\
\hline $6-10$ years & 22 & 14.9 \\
\hline$>10$ years & 7 & 4.7 \\
\hline Total & 148 & 100 \\
\hline \multicolumn{3}{|c|}{ Average FBG (mg/dL) } \\
\hline$<80$ & 8 & 5.4 \\
\hline 80-130 & 74 & 50 \\
\hline$>130$ & 66 & 44.6 \\
\hline Total & 148 & 100 \\
\hline \multicolumn{3}{|l|}{ Comorbidity } \\
\hline Hypertension & 30 & 20.3 \\
\hline $\mathrm{CHF}$ & 7 & 4.7 \\
\hline Dyslipidemia & 4 & 2.7 \\
\hline $\mathrm{HD}$ & 3 & 2.03 \\
\hline Others $^{\mathrm{a}}$ & 7 & 4.7 \\
\hline Total & 51 & 34.5 \\
\hline \multicolumn{3}{|l|}{ Complication } \\
\hline Nephropathy & 7 & 4.7 \\
\hline Retinopathy & 2 & 1.4 \\
\hline Total & 9 & 6.1 \\
\hline
\end{tabular}

a COPD and asthma

comorbid conditions, Enalapril 25 (22.1\%), Nifedipine 16 (14.2\%), hydrochlorothiazide 15 (13.3\%) and aspirin 14 (12.4\%) were most frequently prescribed medications. Only $12(8.1 \%)$ of the participants were taking 5 drugs and above (Table 2).

From the total 148 PMRs, 95 (64.2\%) patients had at least one DRP identified and a total of 127 DRPs were identified, which is 0.9 DRPs per patient. Among patients with DRP, more than half of them, $59(62.1 \%)$ had a single DRP and 36 (37.9) of them had double DRP. Dosage
Table 2 Prescribed medications for ambulatory patients with type 2 diabetes on follow up at HFSUH from JulyDecember 2018, Harar, Ethiopia

\begin{tabular}{lcl}
\hline Medications & Frequency & Percentage \\
\hline Anti-diabetic medications & & \\
Metformin & 55 & 37.2 \\
Metformin + glibenclamide & 41 & 27.7 \\
Basal insulin & 24 & 16.2 \\
Metformin + basal insulin & 19 & 12.8 \\
Glibenclamide & 6 & 4.1 \\
Glibenclamide+ basal insulin & 3 & 2 \\
Total & 148 & 100 \\
Other medications & & \\
Enalapril & 25 & 22.1 \\
Nifedipine & 16 & 14.2 \\
Hydrochlorothiazide & 15 & 13.3 \\
Aspirin & 14 & 12.4 \\
Atorvastatin & 10 & 8.8 \\
Metoprolol & 8 & 7.1 \\
Anti-asthmatics & 7 & 6.2 \\
Furosemide & 7 & 6.2 \\
Others & 11 & 9.7 \\
Total & 113 & 100 \\
Total number of drug per patient & & 91.9 \\
$<5$ & 136 & 100 \\
$\geq 5$ & 12 & \\
Total & & \\
\hline a Spironolactone, amitriptyline and benzyl penicillin &
\end{tabular}

a Spironolactone, amitriptyline and benzyl penicillin

too low was the most common type of DRP encountered, $46(36.2 \%)$, followed by unnecessary drug therapy, 25 (19.7\%) and ineffective drug therapy, 25 (19.7\%) (Table 3).

\section{Discussion}

In the current study, a total of 127 DRPs were identified from 148 PMR, which is 0.9 DRPs per patient. $64.2 \%$ of the patients had a DRP problem identified. This is lower than the result obtained in Wolaita Soddo, southern Ethiopia, which showed that $83.1 \%$ of T2DM patients had at least one DRP with the mean number of $1.8 \pm 0.751 \mathrm{DRPs}$ [2] and with Danish study which shows an average of 4.1 DRPs per patients [23]. The discrepancy with these studies could be due to the use of different data collection methods since the study conducted in Wolaita Soddo also include interviewer-administered questionnaire and difference in the study protocol since the Danish study uses Problem Intervention Documentation (PI-DOC). Socio-demographics and co-morbid conditions of study patients could also affect the DRP. The individuals with co-morbid conditions in the current study account for $34.5 \%$ of the study population, which is lesser than the 
Table 3 Drug related problems among ambulatory patients with type 2 diabetes on follow up from July to December 2018 at HFSUH, Harar, Ethiopia

\begin{tabular}{|c|c|c|}
\hline DRPs & Frequency & Percentage \\
\hline \multicolumn{3}{|l|}{ Number of patients with DRP } \\
\hline Single DRP & 59 & 62.1 \\
\hline Double DRPs & 36 & 37.9 \\
\hline Total & 95 & 100 \\
\hline \multicolumn{3}{|l|}{ Types of DRPs } \\
\hline Dosage too low & 46 & 36.2 \\
\hline Metformin + glibenclamide & 10 & 7.9 \\
\hline Meftormin + basal insulin & 13 & 10.2 \\
\hline Metformin & 18 & 14.2 \\
\hline Basal insulin & 5 & 3.9 \\
\hline Ineffective drug & 25 & 19.7 \\
\hline Basal insulin alone & 8 & 6.3 \\
\hline Metformin alone & 1 & 0.8 \\
\hline Glibenclamide & 3 & 2.4 \\
\hline Metformin + basal insulin & 5 & 3.9 \\
\hline Metformin + glibenclamide & 6 & 4.7 \\
\hline Basal insulin + glibenclamide & 2 & 1.6 \\
\hline Unnecessary drug therapy & 25 & 19.7 \\
\hline Basal insulin as unnecessary & 10 & 7.9 \\
\hline Glibenclamide as unnecessary & 15 & 11.8 \\
\hline Need for additional drug therapy & 17 & 13.4 \\
\hline Taking metformin alone & 12 & 9.4 \\
\hline Taking metformin and glibenclamide & 3 & 2.4 \\
\hline Taking glibenclamide & 2 & 1.6 \\
\hline Adverse drug reaction & 12 & 9.4 \\
\hline Metformin & 2 & 1.6 \\
\hline Glibenclamide & 6 & 4.7 \\
\hline Basal insulin & 4 & 3.1 \\
\hline Dosage too high & 2 & 1.6 \\
\hline Basal insulin & 2 & 1.6 \\
\hline Total DRPs & 127 & 100 \\
\hline
\end{tabular}

study done in Wolaita Soddo (56\%). Another result from Malaysia's study also showed a higher average DRP $(2.37 \pm 1.40)$ than the current study [17]. This difference could be attributed to the difference in the study population, since the study in Malaysia only involves T2DM patients with dyslipidemia and also due to the difference in the study protocol, with the Malaysian study using Pharmaceutical Care Network Europe (PCNE). Also, the lower level of DRP reported in the current study could also be attributed to the lesser number of medications taken by the patients, with only $8.1 \%$ of the patients taking more than five medications at a time.

The common DRP identified in the current study were dosage too low (36.2\%), ineffective drug (25\%) and unnecessary drug therapy (25\%). This is different from a study done in Malaysia, where the two most common DRP classifications identified in the current study were "potential interaction (18\%)" and "drug not taken or administered at all (14.3\%)" [17]. Inappropriate use of medicine (26.9\%) and inappropriate choice of medicine (9.1\%) were the commonly documented DRP in a Danish study [23]. The difference in the frequency of various DRPs from the current study could be attributed to the difference in the methodology (such as a medical review or interview technique) and types of DRP classification (such as Cipolle, PCNE or PI-Doc system) used. The DRP problems could also occur due to the problem of inadequate follow up at HFSUH and could be due to the absence of some laboratory findings such as hemoglobin $\mathrm{A} 1 \mathrm{C}$ (HbA1C). Such inadequate follow up could be due to the higher workload on the working health care practitioners at HFSUH. One way of reducing DRP is involving a clinical pharmacist, who may assess DRPs in different settings: in hospital multidisciplinary teams, in nursing homes and in primary care [12]. The involvement of clinical pharmacists as a member of the healthcare team helps in the identification and prevention of DRPs which will help to rationalize drug therapy, achieve better therapeutic outcomes and improved the quality of patient care [3].

Dosage too low type of DRPs constituted $36.2 \%$ of the total DRPs in the current study. This report was higher than the study done in Indonesia which was 7.3\% [6], a study that was done in Wolaita Soddo (26.75\%) [2] and the study done in southwest Ethiopia (Jimma specialized hospital) which covered $15.8 \%$ [24]. Such a high prevalence of dosage too low in the current study has been associated with a higher number of T2DM patients (44.6\%) not attaining the desired fasting blood glucose (FBG). This difference could due to the difference in the study population between the current study and the study done in Indonesia and Southwest Ethiopia.

From the total 148 PMRs, 95 (64.2\%) of the patients had one or two DRPs identified. Among those, more than half of the patients, $62.1 \%$ of them had a single DRP. This result is lower than the result obtained in Malaysia, which shows that $90.5 \%$ of the patients had at least one DRP [10], the study done in India, which shows that $71 \%$ of the patients had at least one DRP [3] and the study that was done in southwest Ethiopia, which revealed that $82 \%$ of the participants had at least one drug-related problem [24]. This variation across the studies can be attributed to the fact that the study population in Malaysia, India and southwest Ethiopia is T2DM patients with hypertension problem, which is different from the current study. The difference in DRP identified could also be due to the different study methods used by these studies. There exists 
also a difference in the number of medications used by the patients. In the current study, only $8.1 \%$ of the study population uses more than 5 medications which is less than the result obtained in southwest Ethiopia, which shows that $34 \%$ of them use more than 5 medications, which will increase the risk of DRPs.

In the current study, ADR (9.4\%) and dosage too high (1.6\%) were less frequently occurring DRPs. This is similar to a study in southwest Ethiopia, where these two accounted for the less frequently occurring DRPs [24]. This is different from a study done in Nigeria, which showed ADR was the leading DRP 108 (35.3\%) [11]. Such difference could be attributed to the difference in the age group of the study population, with the mean age of the current study is $51.26 \pm 7.08$ and that of the Nigerian study is $61.4 \pm 12.8$ [11]. The higher incidence of ADR could be attributed to the fact that likely hood of having DTPs increases as the age of respondents increases [2,3]. The absence of laboratory findings such as liver function test and kidney function indicators in the PMR used to assess ADR could also be another reason why ADR was one of the less frequently experienced DRP in the current study. The less number of medications taken by the patients $(8.1 \%)$ could also reduce the chance of drug interaction, reducing the chance of ADR.

\section{Conclusion}

More than half of the participants had at least one DRP identified, with dosage too low, ineffective drug and unnecessary drug therapy being the common DRPs. Out of the 148 patients, only half of the patients have attained the desired FBG level. The present result underscored the need to promote pharmaceutical care at all levels of health care especially in chronic disease management to eliminate DRP and improve treatment outcomes. The involvement of clinical pharmacists in chronic follow up units is very important to reduce DRPs and they should work in collaboration with other health care professionals. Some laboratory findings used to assess ADR were missing, so better documentation is necessary for the betterment of treatment.

\section{Limitation of the study}

The major limitations of the study were that the evaluation relied merely on the records of patients, for which all necessary information was not recorded such as laboratory value hence the DRP was difficult to determine. Since this study was a retrospective study, it doesn't determine the DRPs that are associated with inappropriate use of the medications by the patients (doesn't cover the DRP associated with adherence). This study is also a cross-sectional type and thus it did not investigate cause and effect relationship and also the small sample size makes it difficult to generalize the findings to the general population. Hence, further studies, which take these variables into consideration, will be needed to solve these limitations.

\section{Abbreviations}

ADR: adverse drug reaction; DM: diabetes mellitus; DRPs: drug related problems; HFSUH: Hiwot Fana Specialized University Hospital; PMR: patients' medical records; T2DM: type 2 diabetes mellitus.

\section{Acknowledgements}

The authors are thankful to all individuals who were involved in the research.

\section{Authors' contributions}

HA designed the study, collected data and analyzed data. YT reviewed the study plan, questionnaires and the article, analyzed data and reviewed the manuscript. NL reviewed the article, analyzed data and reviewed the manuscript. All authors read and approved the final manuscript.

\section{Funding}

This study received no support from a funding agency.

\section{Availability of data and materials}

The datasets used and/or analyzed during the current study are available from the corresponding author on reasonable request.

\section{Ethics approval and consent to participate}

A letter of ethical clearance was obtained from Haramaya University, College of Health and Medical Sciences and submitted to the HFSUH to obtain permission to conduct the research. All data obtained in the course of the study were kept confidential and used solely for the purpose of the study.

\section{Consent for publication}

Not applicable.

\section{Competing interests}

The authors declare that they have no competing interests.

Received: 27 August 2019 Accepted: 24 October 2019

Published online: 27 November 2019

\section{References}

1. American Diabetes Association. Standards of medical care in diabetes. Diab Care. 2019;42(Suppl 1):s13-28.

2. Koyra HC, Tuka SB, Tufa EG. Epidemiology and predictors of drug therapy problems among type 2 diabetic patients at Wolaita Soddo University Teaching Hospital, Southern Ethiopia. Am J Pharmacol Sci. 2017;5(2):40-8

3. Shareef J, Fernandes J, Samaga LN. Clinical pharmacist interventions in drug therapy in patients with diabetes mellitus and hypertension in a university teaching hospital. Int J Pharm Sci Res. 2015;6(10):4424-32.

4. Van Roozendaal BW, Krass I. Development of an evidence-based checklist for the detection of drug-related problems in type 2 diabetes. Pharm World Sci. 2009;31(5):580-95.

5. Radwan M, Elsous A, Al-Sharif H, Mustafa AA. Glycemic control among primary care patients with type 2 diabetes mellitus in the Gaza Strip. Palestine. Ther Adv Endocrinol Metab. 2018;9(1):3-14.

6. Zazuli Z, Rohaya A, Adnyana IK. Drug-related problems in type 2 diabetic patients with hypertension: a prospective study. J Basic Clin Pharm. 2017;11(2):S298-304.

7. Brahmbhatt SV, Sattigeri BM, Nil AK, Parikh DP, Shah HS. A prospective study on drug utilization pattern \& rationality in the treatment of type II diabetes mellitus: a population-based analysis. Int J Res Med Sci. 2014;2(3):983-7. 
8. Bp SK, Dahal P, Venkataraman R, Fuloria PC. Assessment of clinical pharmacist intervention in tertiary care hospital of India. Asian J Pharm Clin Res. 2013;6(suppl 2):258-61.

9. Al Hamid A, Aslanpour Z, Aljadhey H, Ghaleb M. Hospitalisation resulting from medicine-related problems in adult patients with cardiovascular diseases and diabetes in the United Kingdom and Saudi Arabia. Int J Environ Res Public Health. 2016;13(5):479.

10. Zaman Huri H, Fun Wee H. Drug-related problems in type 2 diabetes patients with hypertension: a cross-sectional retrospective study. BMC Endocr Disord. 2013;13:2.

11. Ogbonna B, Amagba C. Investigation of drug therapy problems in type 2 diabetes outpatients with comorbid hypertension in a tertiary hospital in Southeast Nigeria. Value Health. 2017;20(9):A859.

12. Viktil KK, Blix HS. The impact of clinical pharmacists on drug-related problems and clinical outcomes. Basic Clin Pharmacol Toxicol. 2008;102(3):275-80.

13. Al-Azzam SI, Alzoubi KH, AbuRuz S, Alefan Q. Drug-related problems in a sample of outpatients with chronic diseases: a cross-sectional study from Jordan. Ther Clin Risk Manag. 2016;12:233-9.

14. Chung AY, Anand S, Wong IC, Tan KC, Wong CF, Chui WC, et al. Improving medication safety and diabetes management in Hong Kong-a multidisciplinary approach. Hong Kong Med J. 2017;23(2):158-67.

15. Anagha V, Wincent MM, Potrilingam D, Jacob SC, Andhuvan G. Assessment of drug-related problems in patients with chronic diseases in the general medicine units of a tertiary care hospital. Int J Pharm Pharm Sci. 2017;9(12):194-200

16. Al-Taani GM, Al-Azzam SI, Alzoubi KH, Darwish Elhajji FW, Scott MG, Alfahel $\mathrm{H}$, et al. Prediction of drug-related problems in diabetic outpatients in a number of hospitals, using a modeling approach. Drug Healthc Patient Saf. 2017;9:65-70.

17. Zaman Huri H, Chai Ling L. Drug-related problems in type 2 diabetes mellitus patients with dyslipidemia. BMC Public Health. 2013;13:1192. https:// doi.org/10.1186/1471-2458-13-1192.
18. Ali I, Khan JZ, Khan AU, Ullah I, Ahmad F. Pharmacotherapy evaluation of diabetic patients inward of general medicine, Northwest general hospital \& research center, a case study from Khyber Pakhtunkhwa. Pakistan. Pharmacol Online. 2015;1:104-8.

19. Andreazza RS, De Castro MS, Köche PS, Heineck I. Causes of drug-related problems in the emergency room of a hospital in southern Brazil. Gac Sanit. 2011;25(6):501-6.

20. Demoz GT. Drug therapy problems among ambulatory Patients with type 2 Diabetes at Endocrine and Metabolism Unit of Tikur Anbessa Specialized Hospital, Addis Ababa. Ethiopia. 2018. http://etd.aau.edu.et/handl e/123456789/13119. Accessed 20 Apr 2018.

21. Cipolle RJ, Strand LM, Morley PC. Pharmaceutical care practice: the patient-centered approach to medication management. 3rd ed. New York: McGraw Hill; 2012

22. FMHACA (Food, Medicine and Health care Administration and Control Authority). Standard treatment guidelines for General Hospitals. Third edition. 2014. http://www.fmhaca.gov.et/wp-content/uploads/2019/03/ STG-General-Hospital.pdf.

23. Haugbolle LS, Sorensen EW. Drug-related problems in patients with angina pectoris, type 2 diabetes and asthma-interviewing patients at home. Pharm World Sci. 2006;28(4):239-47.

24. Yimama M, Jarso H, Desse TA. Determinants of drug-related problems among ambulatory type 2 diabetes patients with hypertension comorbidity in Southwest Ethiopia: a prospective cross-sectional study. BMC Res Notes. 2018;11(1):679. https://doi.org/10.1186/s13104-018-3785-8.

\section{Publisher's Note}

Springer Nature remains neutral with regard to jurisdictional claims in published maps and institutional affiliations.
Ready to submit your research? Choose BMC and benefit from:

- fast, convenient online submission

- thorough peer review by experienced researchers in your field

- rapid publication on acceptance

- support for research data, including large and complex data types

- gold Open Access which fosters wider collaboration and increased citations

- maximum visibility for your research: over $100 \mathrm{M}$ website views per year

At $\mathrm{BMC}$, research is always in progress.

Learn more biomedcentral.com/submissions 